\title{
Heart rate and 123I-MIBG in heart failure with preserved ejection fraction: More variability and slower washout-A secret recipe for better survival
}

\author{
Wael AlJaroudi, MD, FASNC ${ }^{\mathrm{a}}$ \\ a Division of Cardiovascular Medicine, Clemenceau Medical Center, Beirut, Lebanon
}

Received Oct 30, 2018; accepted Oct 30, 2018

doi: $10.1007 / \mathrm{s} 12350-018-01514-w$

See related article, pp. 833-842

\section{AUTONOMIC NERVOUS SYSTEM}

The autonomic nervous system (ANS) regulates physiological processes such as blood pressure and heart rate (HR) among many others, through two major divisions: the sympathetic and parasympathetic systems. The former activates the fight-or-flight mechanisms, while the latter conserves energy and restores it. A delicate homoestasis exists, and this relationship is known as sympathovagal balance. ${ }^{1}$

The HR is an indirect manifestation of this sympathovagal balance and is an indicator of ones' health. Indeed, higher variations in HR indicate a well-balanced autonomic function, while a steady HR with low variability indicates a low parasympathetic tone. ${ }^{2}$ This balance can be offset in many diseases, involve any organ of the body, be peripheral or central in origin, due to primary or secondary causes, temporary or permanent.

Therefore, the ANS may serve as a barometer to one's health. In patients with heart failure (HF) for instance, the balance between the sympathetic and parasympathetic nervous system is offset in favor of an unchecked excess sympathetic tone though activation of the renin-angiotensin system, an increased norepinephrine levels (equally in patients with HF with

\footnotetext{
Funding None.

Reprint requests: Wael AlJaroudi, MD, FASNC, Division of Cardiovascular Medicine, Clemenceau Medical Center, Beirut, Lebanon; wjaroudi@hotmail.com

J Nucl Cardiol 2020;27:843-8.

$1071-3581 / \$ 34.00$

Copyright (C) 2018 American Society of Nuclear Cardiology.
}

reduced and preserved ejection fraction), ${ }^{34}$ and withdrawal of parasympathetic tone. ${ }^{1,5}$

\section{AUTONOMIC DYSFUNCTION AND CARDIOVASCULAR DISEASE: A MISSING LINK?}

Autonomic dysfunction, especially lower parasympathetic activity, is associated with the risk of development and progression of coronary heart disease. ${ }^{6,7}$ Low parasympathetic tone in particular, as evidenced by increased resting HR and decreased Valsalva ratio, is associated with high carotid intima media thickness and elevated coronary artery calcium score among diabetic patients ${ }^{8}$; this highlights the association between autonomic dysfunction and subclinical coronary artery disease. In addition, it has been hypothesized that increased cardiac sympathetic tone increases mitochondrial reactive oxygen species production that leads to myocardial apoptosis, promoting myocardial remodeling and decrease in myocardial vascularity, with subsequent reduction of the coronary blood flow reserve. ${ }^{9}$

Furthermore, reduced HR variability (HRV) was shown to be associated with blunted nocturnal blood pressure drop, ${ }^{10}$ paroxysmal atrial fibrillation, ${ }^{11}$ and silent ischemia, ${ }^{7}$ which are associated with HF with preserved ejection fraction. Indeed, in the current manuscript by Hashimoto et al., $44 \%$ of patients with $\mathrm{HF}$ and preserved ejection fraction had low HRV and increased 123I-MIBG washout-rates, both indicators of autonomic dysfunction. ${ }^{12}$ Given the increased evidence linking autonomic dysfunction with premature cardiovascular disease, silent ischemia and diastolic dysfunction, it is not surprising to see an association with increased cardiovascular events. 


\section{AUTONOMIC DYSFUNCTION AND MAJOR CARDIOVASCULAR ADVERSE EVENTS}

Epidemiological studies strengthen the association between cardiovascular autonomic dysfunction and mortality risk, ${ }^{13}$ with data showing incremental prognostic value beyond traditional risk factors, and consistent results across study groups, patient cohorts, disease spectrum, and testing modalities. ${ }^{14}$ Among elderly patients without known history of cardiac disease, Tsuji et al. showed increased risk for sudden cardiac events among those with reduced autonomic activity. ${ }^{2}$ One of the proposed mechanism is that the excess sympathetic activity predisposes to malignant arrhythmia. This was latter on re-tested and validated using 123I-MIBG imaging, a direct tool to image autonomic function, in which low heart-to-mediastinal ratio was an independent predictor of ventricular arrhythmia. $^{15}$

In addition, a decreased HRV, specifically very-low resting parasympathetic activity, was shown in several studies to be associated with worse outcomes. ${ }^{2,16} \mathrm{HR}$ turbulence, a type of HRV analysis, was also shown in one of the first prospective studies to be associated with fatal and nonfatal cardiac arrest in seemingly low-risk post-acute myocardial infarction cohort. ${ }^{17}$ Therefore, abnormal cardiac autonomic activity is associated with a post-MI mortality, sudden cardiac and all-cause death. This highlights the need for autonomic testing to riskstratify for major cardiovascular events. ${ }^{18}$

\section{TESTING FOR AUTONOMIC DYSFUNCTION}

Cardiac sympathetic nerve imaging allows direct assessment of the integrity of the adrenergic cardiac innervation. ${ }^{19}$ This is performed using hydroxyephedrine labeled with carbon-11 [11CHED] positron emission tomography (PET) or methylated 11carbon-labeled radiotracer 3-quinuclidinyl benzilate (11C-MQNB). The former is a sympathetic analog, while the latter, an atropine analog, evaluates the parasympathetic nervous system. ${ }^{20}$ These tracers reflect the integrity of the autonomic system and have prognostic value. ${ }^{21}$

The limited availability of PET and high cost, however, limit its routine use. Single photon emission computed tomography (SPECT) imaging with 123iodine metaiodobenzylguanidine [123-I MIBG] on the other hand, is an attractive alternative. 123I-MIBG is a false neurotransmitter that uses the same uptake and storage mechanisms as the endogenously produced neurotransmitter norepinephrine; hence, its kinetics reflects the integrity and function of cardiac presynaptic sympathetic nerve terminals. ${ }^{22}$ The most commonly used semi-quantitative parameters of 123-I MIBG uptake are the heart-to-mediastinum ratio and washoutrate; reduced heart-to-mediastinum ratio and high washout-rate are indicators of autonomic dysfunction and have prognostic value, ${ }^{23-25}$ including sudden cardiac death. ${ }^{15,26,27}$ They also correlate with the degree of coronary artery stenosis, which suggests that the cardiac adrenergic nerve endings function is modified even in mild coronary artery disease before denervation occurs. ${ }^{28}$ This explains why cardiac 123I-MIBG scintigraphy may diagnose autonomic dysfunction in early stages before clinical manifestations such as reduced $\mathrm{HRV}^{29,30}$

While direct imaging of the ANS is more accurate, there is a need for simpler and more accessible tools to evaluate the ANS. These includes: (1) cardiovagal innervation testing, which evaluates the integrity of the parasympathetic system through heart rate response to deep breathing and to the Valsalva maneuver; and (2) vasomotor adrenergic innervation that evaluates the integrity of the sympathetic system through beat-to-beat blood pressure response to the head-up tilt and Valsalva maneuver. A list of tools to measure ANS is summarized in Table 1.

To that effect, the HR which is affected by the balance of sympathetic and parasympathetic tones, is an indirect non-invasive reflection of the integrity of ANS. Patients with elevated resting heart rate have lower parasympathetic tone. However, in isolation, a resting HR is not accurate enough to detect autonomic dysfunction. HRV which is a measure of the variation in beat-to-beat intervals in heart rate, is a more powerful tool in assessment of the autonomic function; it is noninvasive, accurate, reproducible, reliable, simple, and quick to process. It is a reflection of the heart-brain interactions and autonomic nervous system dynamics. ${ }^{31}$ In addition, functional imbalances between the sympathetic and parasympathetic nervous systems are further unmasked through respiratory; hence, coupling of HRV with respiratory activity helps identify further the cardiovagal response. ${ }^{32}$

Other tools to detect autonomic dysfunction include heart rate QT variability which can detect subclinical cardiac autonomic neuropathy in diabetic patients, ${ }^{33}$ and HR fragmentation, a marker of sinoatrial node instability and autonomic dysfunction, that also provides incremental prognostic value beyond Framingham in the MESA study. ${ }^{34}$

While HRV analysis requires software analysis and some expertise, there are simpler variables that are readily available and routinely measured that also reflect the integrity of the ANS. HR recovery after exercise stress testing (maximal HR achieved-HR at one minute recovery) and HR reserve, are indicators of the 
Table 1. Assessment tools of autonomic nervous system

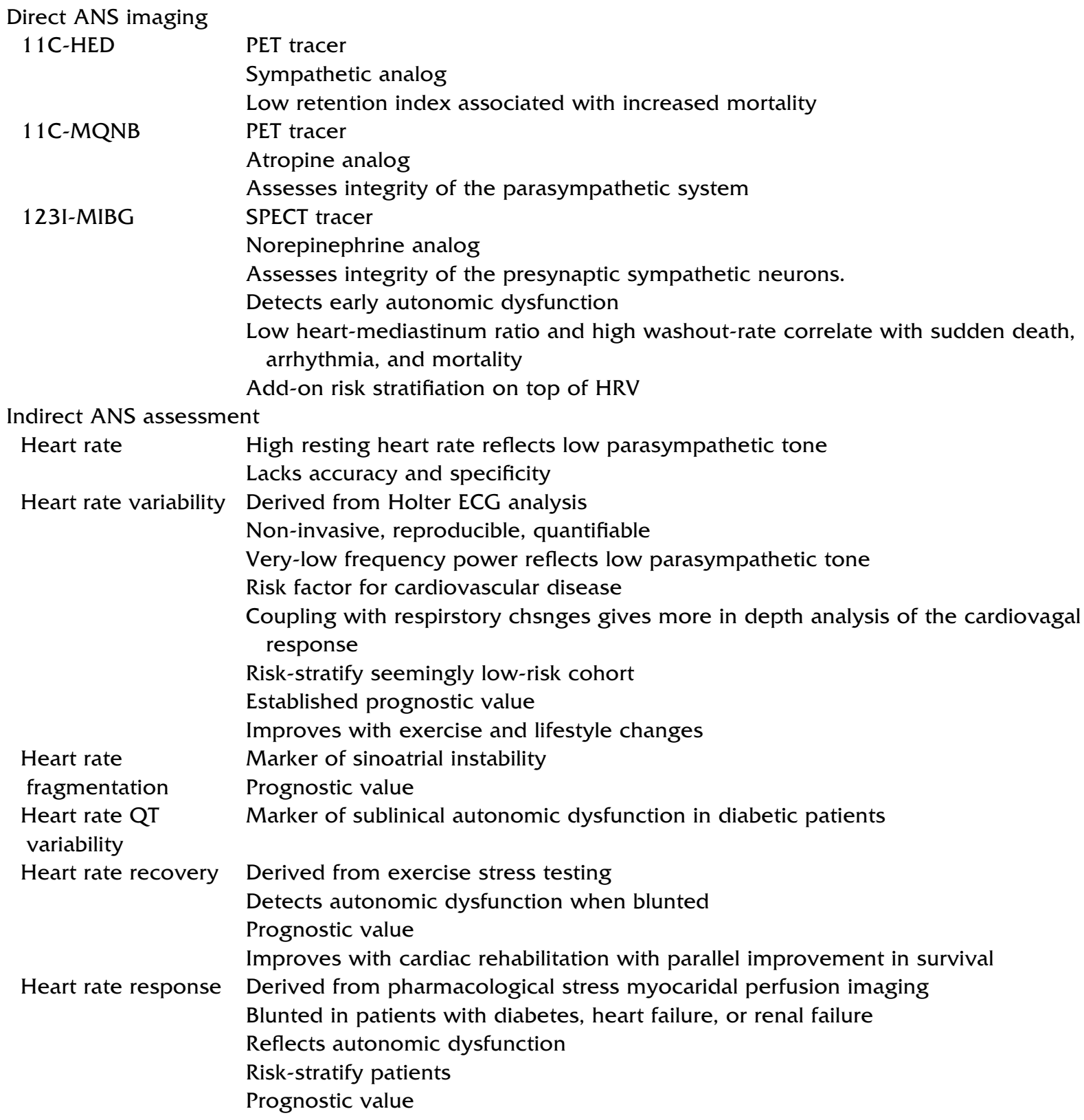

sympathovagal balance. Blunted HR recovery and reserve are associated with increased cardiovascular risk such as hypertension, ${ }^{35}$ coronary artery calcification, ${ }^{36}$ subclinical atherosclerosis, ${ }^{37}$ inflammation and insulin resistance, ${ }^{38}$ and arrhythmia. ${ }^{39}$ In addition, they reflect autonomic dysfunction, ${ }^{40}$ and predict major cardiovascular events. $^{41,42}$

During pharmacological stress myocardial perfusion imaging, HR response can calculated as percentage change from baseline. It is blunted in patients with diabetes and chronic kidney disease, which is thought to be a reflection of autonomic dysfunction. ${ }^{43,44}$ Similar to other markers of autonomic dysfunction, blunted HR response is also an independent predictor of mortality with incremental value beyond traditional risk factors. ${ }^{45-49}$

\section{INTEGRATING HRV AND 123I-MIBG WASHOUT-RATE}

HRV and 123I-MIBG washout-rate are both markers of ANS and with an inverse relationship; they detect early autonomic dysfunction among those without 
known coronary artery disease $\mathrm{e}^{22}$ and asymptomatic patients with end-stage renal disease. ${ }^{50}$

In the current manuscript, Hashimoto et al. identified 133 patients with $\mathrm{HF}$ and preserved ejection fraction who underwent HRV analysis of Holter electrocardiogram and 123I-MIBG SPECT imaging. ${ }^{12}$ Each test was interpreted in a blinded manner, and the results were not available to the treating physician since this was a retrospective study. While low HRV, particularly verylow frequency power [cut-off $825 \mathrm{~ms}^{2}$ ], and high 123IMIBG washout-rate [cut-off value 42\%] were individually associated with increased major adverse cardiovascular events (MACE) in concordance with prior studies (described previously), the addition of the two parameters in the same model was even more predictive of outcomes, as they complimented each other. Indeed, when compared to those with high HRV and low washout-rate (very low-risk group, 55/133 of the cohort, 2\% had MACE after 5.4 years follow-up), those with both low HRV and high washout-rates (veryhigh risk group, 36/133 of the cohort, 61\% had MACE) had significantly higher risk (hazard ratio 40 [5.4-310], $p<0.01)$. Also, among patients with preserved ejection fraction and mild HF symptoms (74\% NYHA I-II), the combination of HRV and 123I-MIBG washout-rate risk stratified two-third of the cohort into either a very-low or very-high risk groups, leaving only a third in the intermediate risk zone. ${ }^{12}$ It is noteworthy that the MACE was driven by hospitalization for HF (21/39), and less so by cardiac death (16/39 with $12 / 39$ related to pump failure). The incidence of sudden cardiac death however, was not clear but likely lower than expected. The selection bias, the small sample size, and the fact that the mean EF of the cohort was $63 \%$ could in part explain why hospitalization and death from heart failure were driving the outcomes with less impact from arrhythmia. In contrast, among patients with reduced ejection fraction undergoing both HRV and 123I-MIBG imaging, HRV was predictor of sudden cardiac death, while 123I-MIBG washout-rate predicted all-cause mortality. ${ }^{51}$

Biologically feasible mechanisms, epidemiological data, and clinical studies support the need to test for autonomic dysfunction, not only in diabetics, but also in the general population as they age and the incidence of heart disease increases. It is well established that autonomic dysfunction, whether measured indirectly (HR variability, response, recovery, etc...) or directly (neuronal imaging), is a cardiovascular risk factor with associated increased cardiac morbidity and mortality. Identifying early autonomic dysfunction can risk-stratify patients, particularly when combining data from both HRV analysis and 123I-MIBG imaging. Indeed, DePace et al. have shown that autonomic dysfunction can be treated if the correction information on the sympathovagal balance is available. ${ }^{1}$ Resuming exercise and daily life activities, or even a simple walk in nature, can improve HRV. ${ }^{52,53}$ Also, HR recovery can be restored back to normal among patients undergoing cardiac rehabilitation, and so does their survival curve. ${ }^{54}$

Therefore, physical and pharmaceutical interventions that improve or restore autonomic function may lead to better prognosis. Early detection and risk stratification remain a key element.

\section{Disclosure}

None.

\section{References}

1. DePace NL, Mears JP, Yayac M, Colombo J. Cardiac autonomic testing and diagnosing heart disease. "A clinical perspective". Heart Int 2014;9:37-44.

2. Tsuji H, Venditti FJ Jr, Manders ES, Evans JC, Larson MG, Feldman CL, et al. Reduced heart rate variability and mortality risk in an elderly cohort. The framingham heart study. Circulation. 1994;90:878-83.

3. Kitzman DW, Little WC, Brubaker PH, Anderson RT, Hundley WG, Marburger CT, et al. Pathophysiological characterization of isolated diastolic heart failure in comparison to systolic heart failure. JAMA 2002;288:2144-50.

4. Levi R, Silver RB, Mackins CJ, Seyedi N, Koyama M. Activation of a renin-angiotensin system in ischemic cardiac sympathetic nerve endings and its association with norepinephrine release. Int Immunopharmacol 2002;2:1965-73.

5. Packer M. The neurohormonal hypothesis: A theory to explain the mechanism of disease progression in heart failure. J Am Coll Cardiol. 1992;20:248-54

6. Liao D, Cai J, Rosamond WD, Barnes RW, Hutchinson RG, Whitsel EA, et al. Cardiac autonomic function and incident coronary heart disease: A population-based case-cohort study. The aric study. Atherosclerosis risk in communities study. Am J Epidemiol. 1997;145:696-706

7. Huikuri HV, Jokinen V, Syvanne M, Nieminen MS, Airaksinen $\mathrm{KE}$, Ikaheimo MJ, et al. Heart rate variability and progression of coronary atherosclerosis. Arterioscler Thromb Vasc Biol. 1999;19:1979-85.

8. Fakhrzadeh H, Yamini-Sharif A, Sharifi F, Tajalizadekhoob Y, Mirarefin M, Mohammadzadeh M, et al. Cardiac autonomic neuropathy measured by heart rate variability and markers of subclinical atherosclerosis in early type 2 diabetes. ISRN Endocrinol 2012;2012:168264.

9. Pop-Busui R, Kirkwood I, Schmid H, Marinescu V, Schroeder J, Larkin D, et al. Sympathetic dysfunction in type 1 diabetes: Association with impaired myocardial blood flow reserve and diastolic dysfunction. J Am Coll Cardiol 2004;44:2368-74.

10. Salles GF, Ribeiro FM, Guimaraes GM, Muxfeldt ES, Cardoso $\mathrm{CR}$. A reduced heart rate variability is independently associated with a blunted nocturnal blood pressure fall in patients with resistant hypertension. J Hypertens 2014;32:644-51.

11. Raman D, Kaffashi F, Lui LY, Sauer WH, Redline S, Stone P, et al. Polysomnographic heart rate variability indices and atrial 
ectopy associated with incident atrial fibrillation risk in older community-dwelling men. JACC Clin Electrophysiol 2017;3:45160 .

12. Hashimoto H, Nakanishi R, Mizumura S, Hashimoto Y, Okamura Y, Yamanaka K, et al. Prognostic values of 123i-mibg myocardial scintigraphy and heart rate variability in patients with heart failure with preserved ejection fractio. J Nucl Cardiol 2018

13. Astrup AS, Tarnow L, Rossing P, Hansen BV, Hilsted J, Parving HH. Cardiac autonomic neuropathy predicts cardiovascular morbidity and mortality in type 1 diabetic patients with diabetic nephropathy. Diabetes Care 2006;29:334-9.

14. Curtis BM, O'Keefe JH Jr. Autonomic tone as a cardiovascular risk factor: The dangers of chronic fight or flight. Mayo Clin Proc 2002;77:45-54.

15. Marshall A, Cheetham A, George RS, Mason M, Kelion AD. Cardiac iodine-123 metaiodobenzylguanidine imaging predicts ventricular arrhythmia in heart failure patients receiving an implantable cardioverter-defibrillator for primary prevention. Heart 2012;98:1359-65.

16. Maser RE, Mitchell BD, Vinik AI, Freeman R. The association between cardiovascular autonomic neuropathy and mortality in individuals with diabetes: A meta-analysis. Diabetes Care 2003;26:1895-901.

17. Bilchick KC, Fetics B, Djoukeng R, Fisher SG, Fletcher RD, Singh SN, et al. Prognostic value of heart rate variability in chronic congestive heart failure (veterans affairs' survival trial of antiarrhythmic therapy in congestive heart failure). Am J Cardiol 2002;90:24-8.

18. Barthel P, Bauer A, Muller A, Junk N, Huster KM, Ulm K, et al. Reflex and tonic autonomic markers for risk stratification in patients with type 2 diabetes surviving acute myocardial infarction. Diabetes Care 2011;34:1833-7.

19. Jb M, Ev C, Jb J. Cardiac autonomic nervous system in heart failure: Imaging technique and clinical implications. Curr Cardiol Rev 2011;7:35-42.

20. Jamali HK, Waqar F, Gerson MC. Cardiac autonomic innervation. J Nucl Cardiol 2017;24:1558-70.

21. Pietila M, Malminiemi K, Ukkonen H, Saraste M, Nagren K, Lehikoinen $\mathrm{P}$, et al. Reduced myocardial carbon-11 hydroxyephedrine retention is associated with poor prognosis in chronic heart failure. Eur J Nucl Med 2001;28:373-6.

22. Simula S, Vanninen E, Hedman A, Lehto S, Kuikka J, Hartikainen J. Myocardial (123) i-metaiodobenzylguanidine washout and heart rate variability in asymptomatic subjects. Ann Noninvasive Electrocardiol 2012;17:8-13.

23. Merlet P, Valette H, Dubois-Rande JL, Moyse D, Duboc D, Dove $\mathrm{P}$, et al. Prognostic value of cardiac metaiodobenzylguanidine imaging in patients with heart failure. J Nucl Med. 1992;33:471-7.

24. Agostini D, Verberne HJ, Burchert W, Knuuti J, Povinec P, Sambuceti G, et al. I-123-mibg myocardial imaging for assessment of risk for a major cardiac event in heart failure patients: Insights from a retrospective european multicenter study. Eur J Nucl Med Mol Imaging 2008;35:535-46.

25. Ogita H, Shimonagata T, Fukunami M, Kumagai K, Yamada T, Asano Y, et al. Prognostic significance of cardiac (123)i metaiodobenzylguanidine imaging for mortality and morbidity in patients with chronic heart failure: A prospective study. Heart 2001;86:656-60.

26. Tamaki S, Yamada T, Okuyama Y, Morita T, Sanada S, Tsukamoto Y, et al. Cardiac iodine-123 metaiodobenzylguanidine imaging predicts sudden cardiac death independently of left ventricular ejection fraction in patients with chronic heart failure and left ventricular systolic dysfunction: Results from a comparative study with signal-averaged electrocardiogram, heart rate variability, and qt dispersion. J Am Coll Cardiol 2009;53:426-35.

27. Boogers MJ, Borleffs CJ, Henneman MM, van Bommel RJ, van Ramshorst J, Boersma E, et al. Cardiac sympathetic denervation assessed with 123-iodine metaiodobenzylguanidine imaging predicts ventricular arrhythmias in implantable cardioverterdefibrillator patients. J Am Coll Cardiol 2010;55:2769-77.

28. Simula S, Vanninen E, Viitanen L, Kareinen A, Lehto S, Pajunen $\mathrm{P}$, et al. Cardiac adrenergic innervation is affected in asymptomatic subjects with very early stage of coronary artery disease. $\mathrm{J}$ Nucl Med 2002;43:1-7.

29. Murata K, Sumida Y, Murashima S, Matsumura K, Takeda H, Nakagawa T, et al. A novel method for the assessment of autonomic neuropathy in type 2 diabetic patients: A comparative evaluation of 123i-mibg myocardial scintigraphy and power spectral analysis of heart rate variability. Diabet Med. 1996;13:266-72.

30. Kreiner G, Wolzt M, Fasching P, Leitha T, Edlmayer A, Korn A, et al. Myocardial m-[123i]iodobenzylguanidine scintigraphy for the assessment of adrenergic cardiac innervation in patients with iddm. Comparison with cardiovascular reflex tests and relationship to left ventricular function. Diabetes. 1995;44:543-549

31. Heart rate variability. Standards of measurement, physiological interpretation, and clinical use. Task force of the european society of cardiology and the north american society of pacing and electrophysiology. Eur Heart J. 1996;17:354-381

32. Badra LJ, Cooke WH, Hoag JB, Crossman AA, Kuusela TA, Tahvanainen $\mathrm{KU}$, et al. Respiratory modulation of human autonomic rhythms. Am J Physiol Heart Circ Physiol 2001;280:H2674-88.

33. Imam MH, Karmakar CK, Khandoker AH, Jelinek HF, Palaniswami M. Heart rate independent qt variability component can detect subclinical cardiac autonomic neuropathy in diabetes. Conf Proc IEEE Eng Med Biol Soc 2016;2016:928-31.

34. Costa MD, Redline S, Davis RB, Heckbert SR, Soliman EZ, Goldberger AL. Heart rate fragmentation as a novel biomarker of adverse cardiovascular events: The multi-ethnic study of atherosclerosis. Front Physiol 2018;9:1117.

35. Jae SY, Bunsawat K, Fadel PJ, Fernhall B, Choi YH, Park JB, et al. Attenuated heart rate recovery after exercise testing and risk of incident hypertension in men. Am J Hypertens 2016;29:1103-8.

36. Jae SY, Kurl S, Laukkanen JA, Yoon ES, Choi YH, Fernhall B, et al. Relation of heart rate recovery after exercise testing to coronary artery calcification. Ann Med 2017;49:404-10.

37. Mohlenkamp S, Lehmann N, Schmermund A, Roggenbuck U, Moebus S, Dragano N, et al. Association of exercise capacity and the heart rate profile during exercise stress testing with subclinical coronary atherosclerosis: Data from the heinz nixdorf recall study. Clin Res Cardiol 2009;98:665-76.

38. Kuo HK, Gore JM. Relation of heart rate recovery after exercise to insulin resistance and chronic inflammation in otherwise healthy adolescents and adults: Results from the national health and nutrition examination survey (nhanes) 1999-2004. Clin Res Cardiol 2015;104:764-72.

39. Maddox TM, Ross C, Ho PM, Magid D, Rumsfeld JS. Impaired heart rate recovery is associated with new-onset atrial fibrillation: A prospective cohort study. BMC Cardiovasc Disord 2009;9:11.

40. Georgoulias P, Valotassiou V, Tsougos I. Heart-rate recovery as a clinical marker of cardiovascular autonomic dysfunction in diabetic patients. Eur J Nucl Med Mol Imaging 2009;36:320-1.

41. Hai JJ, Siu CW, Ho HH, Li SW, Lee S, Tse HF. Relationship between changes in heart rate recovery after cardiac rehabilitation on cardiovascular mortality in patients with myocardial infarction. Heart Rhythm 2010;7:929-36. 
42. Maddox TM, Ross C, Ho PM, Masoudi FA, Magid D, Daugherty SL, et al. The prognostic importance of abnormal heart rate recovery and chronotropic response among exercise treadmill test patients. Am Heart J 2008;156:736-44.

43. Hage FG, Heo J, Franks B, Belardinelli L, Blackburn B, Wang W, et al. Differences in heart rate response to adenosine and regadenoson in patients with and without diabetes mellitus. Am Heart $\mathbf{J}$ 2009;157:771-6.

44. Hage FG, Perry G, Heo J, Iskandrian AE. Blunting of the heart rate response to adenosine and regadenoson in relation to hyperglycemia and the metabolic syndrome. Am J Cardiol 2010;105:839-43.

45. Hage FG, Wackers FJ, Bansal S, Chyun DA, Young LH, Inzucchi $\mathrm{SE}$, et al. The heart rate response to adenosine: A simple predictor of adverse cardiac outcomes in asymptomatic patients with type 2 diabetes. Int J Cardiol 2013;167:2952-7.

46. Hage FG, Dean P, Iqbal F, Heo J, Iskandrian AE. A blunted heart rate response to regadenoson is an independent prognostic indicator in patients undergoing myocardial perfusion imaging. J Nucl Cardiol 2011;18:1086-94.

47. AlJaroudi W, Anokwute C, Fughhi I, Campagnoli T, Wassouf M, Vij A, et al. The prognostic value of heart rate response during vasodilator stress myocardial perfusion imaging in patients with end-stage renal disease undergoing renal transplantation. $\mathrm{J} \mathrm{Nucl}$ Cardiol 2017

48. Andrikopoulou E, AlJaroudi WA, Farag A, Lester D, Patel H, Iskandrian $\mathrm{AE}$, et al. The reproducibility and prognostic value of serial measurements of heart rate response to regadenoson during myocardial perfusion imaging. Eur J Nucl Med Mol Imaging 2016;43:1493-502.

49. AlJaroudi W, Campagnoli T, Fughhi I, Wassouf M, Ali A, Doukky R. Prognostic value of heart rate response during regadenoson stress myocardial perfusion imaging in patients with end stage renal disease. J Nucl Cardiol 2016;23:560-9.

50. Chrapko BE, Jaroszynski AJ, Glowniak A, Bednarek-Skublewska A, Zaluska W, Ksiazek A. Iodine-123 metaiodobenzylguanidine myocardial imaging in haemodialysed patients asymptomatic for coronary artery disease: A preliminary report. Nucl Med Commun 2011;32:515-21.

51. Anastasiou-Nana MI, Terrovitis JV, Athanasoulis T, Karaloizos L, Geramoutsos A, Pappa L, et al. Prognostic value of iodine-123metaiodobenzylguanidine myocardial uptake and heart rate variability in chronic congestive heart failure secondary to ischemic or idiopathic dilated cardiomyopathy. Am J Cardiol 2005;96:427-31.

52. Nakayama N, Negi K, Watanabe K, Hirai M. Life activities improve heart rate variability in patients with mild hypertension and/or the initial stage of heart failure. J Clin Nurs 2014;23:36773.

53. Gladwell VF, Kuoppa P, Tarvainen MP, Rogerson M. A lunchtime walk in nature enhances restoration of autonomic control during night-time sleep: Results from a preliminary study. Int $J$ Environ Res Public Health 2016;13

54. Jolly MA, Brennan DM, Cho L. Impact of exercise on heart rate recovery. Circulation 2011;124:1520-6. 